\title{
Bairros, Bairros Suburbanos e Subcentros ${ }^{1}$
}

\author{
Maria Therezinha Segadas Soares
}

Os bairros e bairros suburbanos ocupam 38,5\% da área do Estado da Guanabara, abrigando $66,5 \%$ de sua população. Um enorme contingente populacional habita essas duas unidades urbanas que se caracterizam, justamente, pelo total preenchimento de espaço e pelas elevadas densidades populacionais.

Dentro de cada uma dessas unidades, certas características da paisagem, do conteúdo social e da função, permitem-nos estabelecer certas diferenciações dentro da área de cada unidade, isto é, dos bairros e bairros suburbanos. São essas diferenciações na ocupação do solo urbano, dentro de cada unidade, que serão objeto de estudo.

Na zona dos bairros da cidade é a diferença na intensidade de ocupação do solo, sem dúvida, o principal elemento de diferenciação fisionômica entre os bairros da Zona Norte e os bairros da Zona Sul.

Os bairros da Zona Norte já realizaram a completa ocupação horizontal do espaço, porém, apresentam uma fisionomia em que o edifício de apartamentos é exceção, havendo uma predominância absoluta das construções térreas ou de dois andares.

O crescente interesse da população da cidade pela Zona Sul não tem incentivado a substituição das construções baixas por grandes edifícios. A pequena importância do crescimento vertical, nessa área, é atestada pelos baixos índices de incremento populacional dos bairros da Zona Norte, que se mantêm em torno de $20 \%$, e pelo decréscimo do incremento nas duas últimas décadas. Esses dados testemunham, não só, o seu total preenchimento horizontal, mas a falta de renovação pelo crescimento vertical. Isso não acontece na Zona Sul, onde até residências com vinte anos de construção já estão sendo demolidas para construção de arranha-céus. Na Zona Norte, só onde a tradição de bairro "chic" - a Tijuca - e a constituição de importante subcentro na Praça Saenz Peña, constituíram atrativos para os compradores, é que se tem intensificado a substituição de prédios antigos por edifícios modernos; isto é comprovado pelo maior índice de incremento populacional da Tijuca (33\%).

Na Zona Sul, a extrema valorização da orla da Baía da Guanabara e da faixa das praias oceânicas levou à crescente substituição das casas por arranha-céus. Estes formam uma verdadeira muralha, nas vias situadas a beira-mar, e vão rareando à medida que a distância da praia vai aumentando. É de notar que, apesar de estarem Flamengo e Botafogo, mais próximos do Centro, e de serem bairros mais antigos, a substituição das velhos casas por arranha-céus, ai, foi mais lenta e ocorreu depois do extraordinário crescimento vertical de Copacabana. Esses bairros, principalmente Botafogo, possuem, ainda, uma grande área ocupada por casas antigas.

Em Copacabana, a intensidade da ocupação do solo atingiu proporção verdadeiramente fantástica, havendo áreas de arranha-céus que, segundo estudo feito em 1958, possuíam 4.600 habitantes por quadra. A Circunscrição de Copacabana (Copacabana e Ipanema) possui 4,33 $\mathrm{km}^{2}$ de área edificada e abriga, segundo o Censo de 1960, uma população de 240.347 habitantes. Essa enorme densidade de ocupação criou graves 
problemas para Copacabana, como insuficiência de rede de esgoto, água, telefone, escolas e congestionamento do trânsito. Até mesmo a localização dos serviços básicos de subsistência e primeira necessidade, para atender à população residente do bairro, constitui um problema, devido ao alto custo do aluguel das lojas, decorrente da enorme importância de Copacabana como subcentro.

Nos bairros de Ipanema e Leblon, cujo início da ocupação data somente de 30 anos, além de já se ter processado toda a ocupação horizontal dos bairros, começou a se realizar, em ritmo muito acelerado, nestes últimos anos, a substituição de casas novas por edifícios de apartamentos em toda a orla praiana e nas vias de circulação principais, paralelas à praia.

A rapidez com que se processou o preenchimento horizontal e o crescimento vertical dos bairros da Zona Sul, principalmente os da orla oceânica, têm na atração pela vida à beira-mar, no clima fresco dessas áreas e em sua beleza natural, a sua explicação. Cada vez é maior o número de habitantes da Zona Norte e, mesmo dos bairros suburbanos, que se muda para a Zona Sul, concorrendo para intensificar o crescimento vertical dessa área, apertada entre a montanha e o mar.

O decréscimo horizontal da Zona Sul, isto é, a conquista de novas áreas para sua expansão constitui um problema. Uma das soluções é a expansão em direção à montanha, o que não é fácil, exigindo técnicas dispendiosas que não estão ao alcance de qualquer um. Assim, essa progressão em direção à montanha está-se processando com um caráter de zona exclusiva das classes ricas, que dispõem de capital para as construções e terrenos caros e dispõem de meios de acesso próprios a essas áreas.

A outra solução para o crescimento horizontal da Zona Sul seria a expansão, além do Leblon, que é grandemente dificultada pela montanha, que aí vem morrer diretamente no mar. Uma estreita e perigosa estrada, recortada na rocha viva, é a única via de acesso à praia da Gávea, e, a seguir, a grande planície de Jacarepaguá.

Essa expansão está-se processando lentamente e limitada a duas classes: uma classe rica e outra miserável. A classe rica pode adquirir os terrenos dos loteamentos caríssimos dessa área e, principalmente, dispõe de condução própria, pois o transporte coletivo para essas áreas ainda é muito escassa. A classe miserável se localizou em duas enormes favelas situadas no alto da montanha, em busca de local próximo do grande mercado de trabalho que é a Zona Sul. Essas duas favelas são a do Anglo e da Rocinha, pioneiras na ocupação dessa área de expansão da cidade.

O segundo elemento de diferenciação entre os bairros da Zona Norte e os da Zona Sul está ligado à idade e ao estilo das construções. A Zona Sul, com exceção de Laranjeiras e parte de Botafogo, caracterizam-se por uma fisionomia moderna, decorrente da ocupação recente de certas áreas, como Ipanema, Leblon, Avenida Niemeyer e Praia da Gávea, grande parte da Gávea, ou da renovação das construções nos velhos bairros do Flamengo e Botafogo. Bangalôs da década de 30, edifícios de apartamentos e casa de arquitetura moderna caracterizam a fisionomia da Zona Sul. Enquanto isso, a Zona Norte, apresenta uma fisionomia antiquada com grande predominância de casas de antes de 1930, quando foi ocupada a maioria de seus bairros; com exceção apenas do Grajaú, Engenho Novo, Engenho Velho, São Cristóvão, Tijuca, Andaraí, Rio Comprido e Vila Isabel, são bairros onde a massa das construções é constituída de casarões do fim do 
século XIX, casas térreas ou com porões, geralmente de frente de rua, palacetes com enfeites rebuscados e vilas.

O terceiro elemento de diferenciação entre os bairros da Zona Norte e os da Zona Sul esta ligado ao conteúdo social das duas zonas.

A Zona Sul é mais heterogênea em sua composição social, pois abriga todos os escalões sociais, desde o favelado ao milionário. Pode-se, mesmo, estabelecer um zoneamento social interessante nos bairros da Zona Sul: as ruas à beira-mar, à beira da Lagoa e na montanha, são privilégios da classe rica pelo alto preço das construções, no primeiro caso, a que se soma, no segundo caso, a dificuldade de acesso. A classe média ocupa, predominantemente, as transversais e as paralelas a praia, de pouca circulação. A classe média de menos recursos ocupa, geralmente, apartamentos menores, nas ruas de grande circulação e comércio. Em Copacabana, com exceção da praia, que é privilégio dos ricos, a heterogeneidade na ocupação é total. Edifícios de luxo alternam-se com apartamentos de classe média ou com os "célebres edifícios" de quarto e kitchnette, fruto de uma especulação desenfreada. Essa especulação colocou a zona mais bela da cidade ao alcance de uma classe pobre, ligada ao mercado de trabalho do subcentro de Copacabana que, muitas vezes, se amontoa nesses pequenos apartamentos. Favelas proliferam em todos os bairros da Zona Sul, localizadas nos morros, constituindo um pano de fundo à muralha de edifícios.

A Zona Norte é bem mais homogênea. Nela predomina a classe média, não havendo áreas ou bairros exclusivos de classe rica, com exceção do Alto da Boa Vista. A classe média, em todas as suas gradações, constitui a massa dos habitantes dessa área. A classe rica e a classe pobre aí estão pouco representadas e as favelas, também, são em menor número.

O quarto elemento de diferenciação esta ligado ao conteúdo funcional dessas duas zonas.

$\mathrm{Na}$ Zona Sul existem mais as grandes indústrias que se tinham instalado, em fins do século passado, na Gávea. Com exceção de uma, elas foram demolidas para dar lugar a loteamentos de alto preço e transferidas para outras áreas fora da cidade. Os grandes e antigos casarões de Botafogo ou de Marquês de São Vicente abrigam, porém, numerosas indústrias de porto médio, como a de produtos farmacêuticos. Finalmente, um artesanato numerosíssimo, trabalhando para as lojas do subcentro de Copacabana ou para a clientela da Zona Sul, localizou-se nas salas dos edifícios de Copacabana, ou nas pequenas casas e velhos sobrados de Botafogo. É interessante notar como Botafogo está funcionando como uma zona de obsolescência para esse quase "Centro" que é Copacabana. Seus velhos prédios abrigam, cada dia, maior número de depósitos (especialmente de peças de automóvel), oficinas de todo o tipo, grandes carpintarias, enfim, um conjunto de atividades ligadas ao mercado de Copacabana e à clientela mais abastada da Zona Sul.

A Zona Norte apresenta, ainda, número apreciável de grandes estabelecimentos industriais, ligados a primeira fase de industrialização do Rio. Tijuca, Andaraí, Vila Isabel e São Cristóvão são os principais bairros onde se localizam, ainda, grandes indústrias, embora cercadas pela massa de construções residenciais e sem possibilidade de ampliação. Os velhos casarões da Zona Norte, também abrigam grande número de pequenas indústrias, devido ao espaço amplo e preços acessíveis que oferecem. O artesanato nos 
bairros da Zona Norte, com exceção de São Cristóvão, onde ele e numerosíssimo, mas ligado ao Centro da cidade, é pouco numeroso.

O último elemento de diferenciação entre a Zona Norte e a Zona Sul é relativo ao desenvolvimento dos serviços.

$\mathrm{Na}$ Zona Norte, observamos um desenvolvimento moderado do comércio e serviços. A população de 431.243 habitantes espalhada sobre uma vasta área, a falta de crescimento vertical, a proximidade e a facilidade de ligação com o Centro, por múltiplas vias de acesso, não geraram, na Zona Norte, subcentros da proporção dos da Zona Sul ou dos Bairros Suburbanos. Aí só se constitui um subcentro de proporção ainda modesta, se comparado com os demais, que é a Praça Saenz Peña, ponto de passagem obrigatório dos transportes de vários bairros em direção ao Centro, o ponto tradicional da reunião dos habitantes da planície tijucana.

Além disso, o subcentro de tipo alongado, característico de certos bairros da Zona Sul, ai apresenta, também, proporções modestas, limitando-se a um comércio numeroso, mas de subsistência ou primeira necessidade, localizado em Barão de Mesquita, Haddock Lôbo e Avenida 28 de Setembro. É a Zona Norte, ainda, uma das principais clientes do comércio do Centro da cidade.

Já na Zona Sul, ocupando uma pequena área, com um contingente populacional maior (564.270 hab.), com enorme crescimento vertical, com grande incremento populacional e com maiores problemas de acesso ao Centro, desenvolveu, não só, o colossal subcentro de Copacabana, mas, também, vários outros como o Largo do Machado e os subcentros alongados de Ipanema e Leblon que, cada dia, especializam e elevam mais o padrão dos seus serviços.

Finalmente, a diferenciação entre as duas zonas surge nítida dos próprios dados do Recenseamento que caracterizam a Zona Norte como de baixo incremento populacional, em torno de $20 \%$, e de decréscimo de incremento, atestando a falta de dinamismo, e estagnação dessa Zona, que não pode concorrer com a beleza e as atrações que a Zona Sul oferece e que justificam que nessa se encontra um dos maiores incrementos populacionais da cidade, como o de Copacabana que atingiu 80\% na década 50-60.

Caracterizados os bairros da Zona Norte e da Zona Sul, através dos seus elementos de diferenciação, vamos analisar os bairros suburbanos. Esses bairros são por nós considerados áreas com características predominantemente urbanas, mas com passado próximo suburbano, com importância ainda ponderável do transporte ferroviário e ocupação predominante por uma população de menores recursos. Esses bairros suburbanos abrangem aquelas áreas cuja ocupação, com características nitidamente suburbanas, data dos primeiros trinta anos deste século. Essa área da cidade, assim era caracterizada num artigo intitulado "Recenseamento de 1900", escrito em 1901: "A continuidade da cidade propriamente dita é tal, que em grande parte se torna impossível estabelecer limites entre as paróquias chamadas urbanas e as suburbanas. Todo o percurso da E.F.C.B., até além da estação de Cascadura, é marginado de habitações, formando sem quebra de continuidade inúmeras ruas, que a freqüência e a rapidez do transporte incorporam naturalmente à cidade. O mesmo se dá com relação a vasta planície servida pelas linhas suburbanas do Norte, da Melhoramentos do Brasil e da Rio D'Ouro. Esses subúrbios não têm existência própria e suas relações são íntimas e freqüentes com o Centro da cidade". 
Esse trecho nos faz sentir o passado suburbano próximo dessa área que, hoje, já está totalmente preenchida e apresenta grande número de características urbanas.

Apesar dos aspectos comuns, a heterogeneidade é grande nessa vasta área, o que justifica uma subdivisão em: bairros suburbanos da Central; bairros suburbanos da Leopoldina, Linha Auxiliar e Rio d'Ouro e área vizinha da Avenida Brasil.

Os bairros suburbanos da Central são os de ocupação mais antiga, já se encontrando numa fase de certa renovação das velhas construções. Dotados da maioria dos melhoramentos, abrigam uma população de melhores recursos, dentro da classe média, e funcionalmente, caracterizam-se pela predominância absoluta da função residencial e pelo grande desenvolvimento da função comercial. Nessa área, surgiram dois grandes subcentros da cidade - Méier e Madureira - servindo ao imenso contingente populacional dos bairros suburbanos, que abrigam 912.074 habitantes, e aos habitantes dos subúrbios guanabarinos.

Nesse setor dos bairros suburbanos da Central, deve ser incluída a parte urbanizada de Jacarepaguá, cuja ocupação se processou, tendo como ponto de partida a ligação, por bonde, com Cascadura. Ainda hoje, Jacarepaguá mantém intensas relações com Cascadura e Madureira, e suas conexões predominantes com o Centro da cidade são realizadas por trem ou ônibus que percorrem o itinerário dos bairros suburbanos da Central.

Os bairros suburbanos da Leopoldina, Linha Auxiliar e Rio D'Ouro, deficientes durante longo tempo, em qualidade e quantidade de transporte ferroviário, são de ocupação mais recente, o que explica a maior escassez de melhoramentos urbanos nessa área. A deficiência do transporte ferroviário, a vizinhança de baixadas e do litoral lodoso foram, durante certo tempo, fatores de repulsão do povoamento dessas áreas. A medida que essas baixadas iam sendo drenadas e o litoral aterrado, seu preenchimento se foi processando rapidamente, incrementado pela maioria dos transportes ferroviários e pela abundância de transporte rodoviário, decorrente da abertura da Avenida Brasil.

Nessa área, localiza-se uma população de recursos mais modestos, residindo em pequenas casas, que se dispõem sobre as baixas colinas, típicas dessa zona.

Nesses bairros (Jacarezinho, Del Castilho, Inhaúma, Engenho da Rainha, Vicente de Carvalho, Irajá, Braz de Pina, Penha, Olaria, Ramos e Bonsucesso), a função residencial, soma-se importante função industrial, pois grandes estabelecimentos fabris instalaram-se nos terrenos planos ou levemente ondulados. Maria da Graça com a General Electric, Bonsucesso com a Cerâmica Klabin, Del Castilho com a Tecelagem Nova América, Benfica com a fábrica Gillete e estabelecimentos metalúrgicos, indústrias químicas de Honório Gurgel, fábrica de cimento branco de Irajá e muitas outras indústrias, fizeram, dessa zona, a de maior concentração industrial da cidade.

Esses bairros suburbanos mais recentes e menos densamente povoados não deram origem a nenhum subcentro de importância, utilizando-se dos subcentros da Central e do próprio Centro da cidade para atendimento de suas necessidades mais importantes.

A abertura da Av. Brasil com o aterro de amplo litoral lodoso, deu origem a uma zona que se destaca das anteriores, por seu caráter muito recente e por se utilizar de transporte rodoviário. Essa área, que se alinha ao longo da Av. Brasil ou que se estende entre ela e a E.F. Leopoldina, tem importante função residencial, e possui numerosos estabelecimentos industriais grandes, médios e pequenos, depósitos e sedes de grandes firmas atacadistas, 
oficinas de peças e reparos de automóveis, ligadas ao enorme trânsito de veículos dessa área, que é a porta de entrada da cidade.

È habitada por uma classe média modesta e classe proletária, e quanto ao aspecto das construções se assemelha muito à zona anterior, com a qual ela se solda e se confunde. $O$ caráter recente da ocupação explica a escassez de melhoramentos urbanos que a mesma apresenta. Essa zona utiliza-se menos dos subcentros da Central, com a qual esta ligada por transporte rodoviário; é principalmente cliente do Centro da cidade, com o qual está ligada por transporte rodoviário rápido e freqüente.

Os bairros suburbanos, em conjunto, apresentam-se já totalmente preenchidos, o que é atestado pelos baixos incrementos populacionais (entre 20 e 30\%) na década 5060, e pelo decréscimo desse incremento em todos eles, com exceção de Madureira, entre as duas últimas décadas.

Bairros e Bairros Suburbanos deram origem, na metrópole do Rio de Janeiro, a vários subcentros de maior ou menor importância.

O fenômeno subcentro é comum às grandes metrópoles, onde a expansão urbana vai aumentando as distâncias e levando os moradores a procurarem estabelecimentos mais próximos, em busca, pelo menos, de mercadorias e serviços não especializados.

A metrópole do Rio de Janeiro revela-se, porém, particularmente interessante e digna de estudo nesse setor, pois nela originou-se um subcentro verdadeiramente gigantesco, vários subcentros muito grandes, e a tendência atual é para a multiplicação de pequenos subcentros, de caráter nucleado ou alongado, por toda a cidade.

No estudo dos subcentros, vamos considerar, em primeiro lugar, as causas gerais do seu aparecimento e multiplicação no Rio, e depois, analisar os tipos de localização dos subcentros, dentro da cidade.

O Rio, até os fins do século passado, não ocupava uma grande área, sendo uma cidade onde a população se amontoava no centro e áreas circunvizinhas, devido às limitações impostas pela lentidão dos meios de transporte. Assim, para o bonde-de-burro do século passado ou bonde elétrico, já do primeiro quartel deste século, o Centro era, ainda, um ponto relativamente eqüidistante para as zonas mais povoadas da cidade. $\mathrm{O}$ extraordinário crescimento populacional da cidade, que quase dobrou a sua população nos últimos vinte anos (em 1940: 1.764.141 hab. e em 1960, 3.307.163 hab.), trouxe um notável aumento em área para o Rio, que viu uma massa humana ocupar e preencher a zona recortada pelos eixos ferroviários da Leopoldina, Rio D'Ouro, Linha Auxiliar e Linha Tronco da Central e Ramal Santa Cruz, ao mesmo tempo em que o crescimento vertical da orla marítima se fazia em ritmo acelerado. Esse crescimento axial do Rio resultou no alongamento extraordinário das distâncias entre as zonas de residência e o Centro da cidade. A isso somou-se o crescente congestionamento do trânsito, em função do enorme aumento do número de veículos circulando e da existência de pontos de estrangulamento do tráfego, decorrentes de fatores topográficos, fazendo com que o transporte se tornasse um verdadeiro pesadelo para o carioca, principalmente nas horas de "rush". Cada vez mais o carioca foi procurando prover as suas necessidades em locais mais próximos de sua residência, onde havia condições para o surgimento de subcentros de serviços, por serem pontos de interseção dos transportes ou de passagem obrigatória. Assim, começaram a desenvolver-se subcentros na cidade, como Méier e Madureira, 
servindo aos habitantes da zona ao longo das ferrovias. Para os habitantes da planície tijucana, a Praça Saenz Peña e a rua Haddock Lôbo passaram a atender a parte de suas necessidades, enquanto que Copacabana servia de subcentro aos moradores da Zona Sul e cada vez mais atraía habitantes de toda a cidade, no setor de diversões e no comércio de luxo. Por sua vez, outros subcentros de menor categoria foram surgindo, uns de tipo alongado, como certas ruas comerciais da Zona Norte e da Zona Sul, outros de tipo nucleado como, por exemplo, o Largo do Machado.

Dentro da aglomeração do Rio de Janeiro e, possivelmente, em outras grandes metrópoles, os grandes subcentros apresentam um tipo peculiar de localização. Eles surgiram ou estão surgindo no contato de áreas com densidades demográficas diferentes e dotadas de equipamento diverso. Esses contatos são os da zona urbana com a zona pioneira urbana ou com a zona suburbana. Também, o contato da zona suburbana com a zona pioneira suburbana gerou grandes subcentros.

O extraordinário alongamento das distâncias, nas grandes metrópoles, e, especialmente, no Rio, faz com que áreas em expansão, precisando do apoio próximo para atendimento de suas necessidades, utilizem-se dos serviços das zonas mais povoadas e mais bem equipadas próximas; isso contribui, de maneira decisiva, para o desenvolvimento e a multiplicação dos serviços dessas áreas já povoadas. Os serviços das zonas de contato têm uma clientela dupla: a da zona povoada e a da zona em preenchimento ou em expansão. Assim, o preenchimento da zona suburbana faz-se apoiado na zona equipada mais próxima, isto é, no limite da zona urbana. Da mesma maneira, a expansão da cidade sobre a zona rural faz-se apoiada nos serviços da fronteira suburbana.

Os exemplos do desenvolvimento de grandes subcentros em zonas de contato se multiplicam no Rio: Copacabana foi, durante muito tempo, ponto de apoio da expansão de Ipanema e Leblon, ponto de apoio do preenchimento da Gávea e, ainda, é apoio hoje para a expansão da Av. Niemeyer; o Méier foi o grande apoio do preenchimento da planície, a leste, e da expansão suburbana ao norte, na linha tronco da Central; Madureira é o ponto de apoio do preenchimento atual da zona suburbana; Campo Grande, Nova Iguaçu e Caxias, situados na fronteira da zona suburbana, apóiam, atualmente, a expansão sobre áreas rurais.

Dentro dessa ampla zona de contato, propícia ao aparecimento de subcentros, houve pontos preferenciais para o desenvolvimento do comércio e dos serviços. Esses pontos de cristalização foram, justamente, os pontos de convergência das vias de circulação, em função de elementos do quadro físico ou humano. Os túneis em Copacabana, a garganta do Méier, o corredor de Madureira, foram pontos de convergência das vias de circulação, cuja passagem obrigatória de grande massa humana; oriunda de várias direções, deu origem ao desenvolvimento do comércio e serviço. Em Campo Grande, Nova Iguaçu e Caxias, aos elementos do quadro físico, somaram-se fatores humanos, concorrendo para a convergência das vias de circulação.

Os pontos de convergência ou de cruzamento de vias de circulação importantes têm gerado, também, dentro da cidade, subcentros de menor categoria, como Praça Saenz Pena e Largo do Machado.

Finalmente, um último elemento não pode ser esquecido, na análise dos subcentros: o crescimento vertical. O crescimento vertical é muito importante no desenvolvimento de 
subcentros de menor categoria c na permanência dos grandes subcentros. O crescimento vertical nada mais e que a expansão do povoamento para cima e, por isso, ele também é gerador ou impulsionador de subcentros. O crescimento vertical da própria Copacabana e da zona sul contribui, de maneira decisiva, para estimular seu gigantesco crescimento como subcentro. Da mesma maneira, foi o crescimento vertical que estimulou o desenvolvimento dos subcentros mais modestos de Ipanema, Leblon e Largo do Machado. Finalmente, os sintomas de estagnação do subcentro do Méier, se comparado com a vitalidade de Madureira, demonstrou que o primeiro, perdendo sua condição de contato, só possui, atualmente, a clientela de uma área densamente povoada, mas estagnada, isto é, sem renovação vertical. Os baixos incrementos populacionais na década 1950-60 e o decréscimo do incremento nas duas últimas décadas atestam a estagnação do povoamento e a falta de crescimento vertical da área servida pelo Méier, não estimulando sua ampliação como subcentro.

Em resumo, o contato de áreas demograficamente diversas, a convergência das vias de circulação e o crescimento vertical são os elementos que contribuem para o surgimento e desenvolvimento dos subcentros na aglomeração do Rio de Janeiro.

Uma hierarquia de subcentros pode ser estabelecida dentro do Rio de Janeiro. Existe um subcentro gigantesco que pode ser denominado de subcentro metropolitano, por ser freqüentado, ainda que em caráter ocasional, por todos os habitantes da metrópole. Esse subcentro é Copacabana.

A seguir, existem vários subcentros que podem ser chamados de regionais, por servirem a grandes áreas da aglomeração: são eles Méier, Madureira, Caxias, Nova Iguaçu e Campo Grande.

Finalmente, ha vários subcentros menores, isto é, que servem a áreas mais restritivas, como os subcentros do Largo do Machado, Leblon e Ipanema, ou que, apesar de servirem a áreas amplas, ainda não desenvolveram, grandemente, seus serviços, como a Praça Saenz Peña.

$\mathrm{Na}$ impossibilidade de analisarmos todos os subcentros, comentaremos um exemplo de cada categoria, isto é, estudaremos os subcentros de Copacabana, Madureira e Leblon.

No Rio de Janeiro, o desenvolvimento gigantesco de um subcentro originou a existência de "uma cidade dentro de outra cidade" (Geiger, 195, p.), que é Copacabana.

O surgimento de Copacabana como bairro residencial resultou, sem dúvida, da evolução da vida moderna, com uma grande valorização da vida ao ar livre e duas atividades esportivas. O clima muito fresco da orla oceânica, batida pelos ventos do sul, a extraordinária beleza das praias e dos panoramas, e, sem dúvida, desinteresse das indústrias por essa. Faixa estreita de restingas e praias, conservando-a exclusivamente residencial, foram fatores que contribuíram para a aparecimento e desenvolvimento rápido de bairros residenciais em Copacabana, Ipanema e Leblon. Progressivamente, os imensos areais iam sendo loteados e ocupados, em ritmo rápido, e logo dotados de todos os melhoramentos urbanos. No entanto, foi a explosão demográfica da cidade, após a última guerra, que forneceu o contingente humano para o início do crescimento vertical de Copacabana. Esse crescimento, a partir de 1950, assumiu um ritmo verdadeiramente fantástico, com a substituição, quase que completa, das construções que datavam no máximo de trinta anos, por edifícios de apartamentos e pelo extraordinário desenvolvimento de outras funções nesse bairro até então exclusivamente residencial. 
O intenso crescimento vertical da orla oceânica foi fruto do estrangulamento, do vazio constituído pela zona Av. Niemeyer-Joá, pois só depois dessa área de ocupação e acesso difíceis é que começa a existir, novamente, uma extensa orla litorânea para a expansão da cidade. Na impossibilidade de crescer horizontalmente, o crescimento vertical foi a solução para atender à crescente procura da orla oceânica para moradia. Copacabana, mais antiga, iniciou, então, a substituição das casas por edifícios e preencheu seus vazios como o Bairro Peixoto. Desde cedo, ponto turístico da cidade, logo se tornou o centro de diversões dos moradores dos bairros da zona sul, que freqüentavam seus cinemas, faziam o "footing" na praia e freqüentavam os elegantes bares à beira-mar. A primeira função de Copacabana, como subcentro, foi, pois, a de local de diversões, o que deu, aos habitantes da zona sul, o hábito de freqüentar esse bairro, importantíssimo para o seu posterior desenvolvimento como subcentro. Logo à medida que os demais bairros da zona sul, como Ipanema, Leblon, Lagoa e Gávea, terminavam o seu preenchimento horizontal e iniciavam o vertical, Copacabana começou a desenvolver-se como centro escolar e a multiplicar e especializar o seu comércio, que tinha, na crescente população do bairro e dos bairros vizinhos, a clientela certa. As grandes casas comerciais do Centro compreenderam ser um bom negócio ter uma filial nesse grande centro populacional e, ao instalá-las, faziam-no dentro de padrões mais modernos e de bom gosto que caracterizam as inúmeras lojas que começaram aí a surgir numa progressão verdadeiramente geométrica. Ao mesmo tempo, profissionais de todas as classes, desde o médico ao sapateiro, aí se instalavam por ter uma clientela numerosa à porta. Finalmente, o acesso, a Copacabana, de todas as classes, através dos apartamentos pequenos e de quarto e sala que, por razões especulativas, passaram a predominar nas construções novas, fez com que a classe modesta, que trabalha no comércio e serviços de bairro, aí pudesse residir. Por sua vez, a classe média e pobre que, aos domingos, ia passar o dia em Copacabana, não se conformava mais em residir no ambiente pouco atraente e abafado dos subúrbios cariocas. A multiplicação das linhas de coletivos, ligando vários bairros da zona norte e subúrbios a Copacabana, comprova essa atração que ela exerce sobre a população das outras áreas da cidade.

Disso tudo resultou o fenômeno Copacabana, que possuía uma população de 74.133 hab. em 1940, de 129.249 hab. Em 1950, e que em 1960 possuía 240.347 habitantes, tendo tido de 1950 para 1960 um incremento de 85,96\%, o que é espantoso numa área que, já em 1950, se achava, em grande parte, ocupada verticalmente, e que ocupa somente uma superfície de $4,3 \mathrm{~km}^{2}$. Além da população que aí reside, para Copacabana afluem todos os turistas nacionais e estrangeiros, devido à sua rede de hotéis de luxo. Também empregados e trabalhadores no comércio, nas construções e nas inúmeras oficinas de Copacabana, vêm aumentar o número dos que animam, durante o dia o intenso movimento de Copacabana.

Essa área, que acumula a função residencial com grande número de outras funções típicas dos "centros" de cidade, é hoje o principal centro de diversões para toda a cidade, inclusive para os subúrbios. O seu comércio de luxo variado, numeroso e bem apresentado, tem, como clientela certa, a população de todos os bairros da zona sul, e atrai, também, a população de gosto mais refinado da zona norte. Finalmente para todos os outros tipos de comércio, com exceção do de subsistência e de primeira necessidade, 
Copacabana tem nos 201.505 habitantes do Leblon, Gávea, Lagoa e Botafogo uma clientela certa e assídua que, somada aos 240.347 moradores do bairro, dão às ruas um extraordinário e permanente movimento de pessoas e de veículos, característicos dos "centros" das grandes metrópoles. Por isso, a simples denominação de subcentro não se aplica a Copacabana, que pode ser considerado, muito mais, um desdobramento do "centro" na direção de maior crescimento populacional da metrópole. Geralmente nas cidades em fase de grande crescimento, a área central se desloca na direção geral seguida pela população (Gist e Halbert, 1956, p. 10). No Rio, não houve um deslocamento do "centro", que não tem ampliado sua área e, sim, um desdobramento de multas funções desse Centro em beneficio de Copacabana.

Madureira é o subcentro regional que será tomado como exemplo. Uma minuciosa pesquisa sobre o papel de Madureira como subcentro foi elaborado pelas geógrafas Maria Francisca Cardoso e Maria Emilia Botelho, que será aqui resumida.

Madureira, estação ferroviária suburbana, inaugurada ao fim do século XIX e simples subúrbio residencial até uns 20 anos atrás, deve seu extraordinário desenvolvimento atual as duas razões acima analisadas. Está no limite de uma zona que já é densamente povoada, com outra zona em franca expansão e ainda não dotada de serviços em número e variedade suficientes para atender ao seu intenso crescimento populacional. A isso se soma a localização de Madureira numa zona de estrangulamento do relevo, na estreita passagem existente entre o Morro de Inácio Dias e o Morro do Juramento, onde duas vias férreas se aproximam (a Linha Tronco e a Linha Auxiliar), dando lugar à existência de duas estações: Madureira e Magno. Para aí converge grande número de vias de ligação com os bairros suburbanos e subúrbios da Linha Auxiliar, da Rio D'Ouro e Leopoldina, e com os subúrbios de Jacarepaguá e do Ramal Santa Cruz. Além de ser ponto de passagem obrigatória de vasto fluxo de passageiros, Madureira está ligada por bonde, ônibus e lotação com várias áreas cuja população vai tomar o trem na estação de Madureira. Assim, além dos trens que por aí passam, cerca de 19 composições são ali formadas, diariamente, número que se eleva a 34 composições, aos sábados.

Tudo isso demonstra a importância de Madureira como grande subcentro, servindo a vasta área. Um comércio numerosíssimo e muito variado, onde grande número de filiais do Centro (Esplanada, Ducal, Barki, Ponto Frio, Neno, B. Moreira e Drago) se fazem representar, atesta a vitalidade de Madureira como subcentro comercial. Antigas ruas residenciais próximas das estações de Madureira e Magno transformaram-se ou estão-se transformando em ruas comerciais. Até mesmo um zoneamento comercial já existe em Madureira, com duas zonas de padrão diverso de comércio: uma de comércio de boa apresentação, artigos melhores e mais caros, junto à estação de Madureira e ao Viaduto Negrão de Lima, e outra zona, do comércio mais modesto, junto a estação de Magno na Linha Auxiliar, servindo a população mais modesta desta ferrovia.

Uma delimitação da zona de influência do comércio de Madureira foi feita através da análise das compras a crédito, realizadas durante um mês, em oito grandes firmas de Madureira, filiais do Centro. Esse estudo demonstrou que é patente a projeção de Madureira ao longo da linha tronco da Central e do ramal Santa Cruz, onde tem, como limites de sua influência dominante, Cascadura e Realengo, onde entra respectivamente em concorrência com os subcentros do Méier e Campo Grande. É igualmente intensa, ao longo da 
Linha Auxiliar e da Rio d'Ouro, a influência de Madureira. A zona da Rio d'Ouro está ligada a Madureira por ruas que foram antigas estradas, como a Estrada Marechal Rangel e a estrada Vicente de Carvalho. A atuação de Madureira diminui bastante na Linha da Leopoldina, onde só a Penha é sua grande clientela, ligada pela Estrada Vicente de Carvalho. Finalmente, Jacarepaguá, zona em plena expansão e pouco dotada de serviços, está, também, na zona de influência de Madureira, a ela ligada pela rua Cândido Benício.

É interessante constatar, no estudo da zona de influência de Madureira, que o Méier que ostentou, durante muito tempo, o titulo de "capital dos subúrbios", vem sendo, hoje, preterido por outros concorrentes: o próprio "Centro" da cidade, hoje mais acessível devido ao grande número e à rapidez do transporte, Madureira, dotada de maior vitalidade, e a Praça Saenz Peña.

É, pois, Madureira, atualmente, um importantíssimo subcentro regional, que deve sua vitalidade atual ao fato primordial de sua posição no contato da zona urbana com a zona suburbana.

O terceiro subcentro por nós analisado é um subcentro menor: o Leblon. A aglomeração do Rio de Janeiro está desenvolvendo grande número de subcentros desse tipo, notando-se, mesmo, uma tendência a autonomia crescente de grande número de bairros no setor de artigos padronizados, com uma crescente especialização do comércio e serviços dos grandes subcentros.

Na origem do subcentro do Leblon, vamos constatar a conjunção das três causas acima assinaladas: é o Leblon o contato de uma zona povoada com zonas em expansão (Gávea e Av. Niemeyer com residências suntuosas e duas enormes favelas: a do Anglo e a da Rocinha). Essas duas áreas são desprovidas de serviços. Os de subsistência e primeira necessidade estão ausentes na Av. Niemeyer e são escassos na Gávea, o que fez do Leblon a área de comércio mais próxima dessas duas zonas. Foi o Leblon o ponto terminal, até pouco tempo, das linhas de ligação com a Av. Niemeyer e passagem obrigatória da ligação Gávea-Copacabana, o que Ihe dava clientela desses dois bairros, para o seu comércio. Por sua vez, o extraordinário ritmo do crescimento vertical do Leblon onde até residências de vinte anos já estão sendo demolidas para dar lugar aos edifícios, vem incrementando o desenvolvimento do comércio, que já se apresenta bastante variado, especializado e com inúmeras casas de luxo. É grande, também, o número de agências de bancos, atestando sua categoria de subcentro.

O subcentro do Leblon é do tipo alongado, isto é, o comércio e serviços alongam-se pelas duas vias de circulação intensa, até há pouco tempo, percorridos por bonde. Notase, também, uma certa diferenciação no padrão do comércio dessas duas vias: a rua Dias Ferreira, mais próxima da zona de apartamentos pequenos e do ponto final de ligações com as favelas, apresenta um comércio numeroso, mas de baixo padrão, enquanto que a Av. Ataulfo de Paiva, cruzando a zona de apartamentos e casas de melhor padrão e sendo percorrida pelas conduções oriundas da Gávea, apresenta um comércio de maior especialização e melhor apresentação.

Até há pouco tempo, o ritmo de crescimento do Leblon vinha sendo intenso, mas houve uma certa moderação desse ritmo, decorrente das ligações diretas da Av. Niemeyer e favelas aí situadas com Copacabana, e das ligações, cada vez mais numerosas, da Gávea com Copacabana. 
O estudo dos subcentros, como de toda a geografia urbana, é altamente dinâmico, e qualquer transformação na vida da cidade pode alterar, profundamente, a evolução desses núcleos de cristalização do comércio e dos serviços da cidade. Assim, do estudo dos bairros, dos bairros suburbanos e dos subcentros, que espontaneamente aí surgiram, podemos constatar a necessidade de os planejamentos urbanísticos não se limitarem a orientar a expansão desordenada das metrópoles sobre áreas novas. Um planejamento minucioso, apoiado em estudos detalhados da realidade, deve ser elaborado para resolver os gravíssimos problemas dessas áreas mais antigas, já densamente povoadas, em que o crescimento vertical desordenado, o congestionamento do tráfego, a falta de áreas de recreação, a falta de escolas, insuficiência da rede de esgotos, água e telefone, mostramnos a presente necessidade de planejar a reestruturação dessas áreas, tomando, como pontos de apoio, os subcentros já existentes.

Leia mais:

SOARES, M. T. de Fisionomia e estrutura do Rio de Janeiro. Revista Brasileira de Geografia, 27 (3) 1965, pp. 329-387.

${ }^{1}$ Em FIBGE Curso de Geografia da Guanabara.Rio de Janeiro, 1968. (Série B Biblioteca Brasileira, Publicação n²1), pp, 74-89. 